\title{
A clearer picture of physician income
}

A new measure of physician income called average gross clinical payment, which provides a more comprehensive picture by taking into account both fee-forservice and alternative payment plans, indicates the average doctor in Canada earned \$307 482 in 2010-2011, up $3.1 \%$ from the previous year, according to the Canadian Institute for Health Information (CIHI).

"In the past, we reported on average physician compensation based only on fee-for-service payments, but fee-forservice is a declining proportion of total physician remuneration," says Geoff Ballinger, manager of health human resources at CIHI, which released its latest figures on physician income in the report National Physician Database 2010-2011 (https://secure.cihi.ca/estore /productFamily.htm?locale=en\&pf=PFC 2032\&lang=en\&media $=0$ ).

Though previous reports were "footnoted extensively" to make it clear that figures were based only on fee-forservice payments, there still appeared to be confusion among some readers, says Ballinger. In other words, you would be incorrect if you thought the average physician income figure of $\$ 288549$ indicated in the previous CIHI report on the physician database represented total compensation. Various methodologies were discussed to provide a more accurate indicator of total compensation and the metric settled upon was average gross clinical payment.

"It tends to change the order of the rankings of the provinces, who is making more and who is making less," says Ballinger.

In the current report, the average gross clinical payment ranged from lows of \$235 768 (Prince Edward Island[PEI]) and \$250 486 (Nova Scotia) to highs of $\$ 340020$ (Ontario) and $\$ 349655$ (Alberta). But in the previous report, where provinces were ranked according to gross fee-for-service payments for physicians with at least $\$ 60000$ in payments, the bottom spot

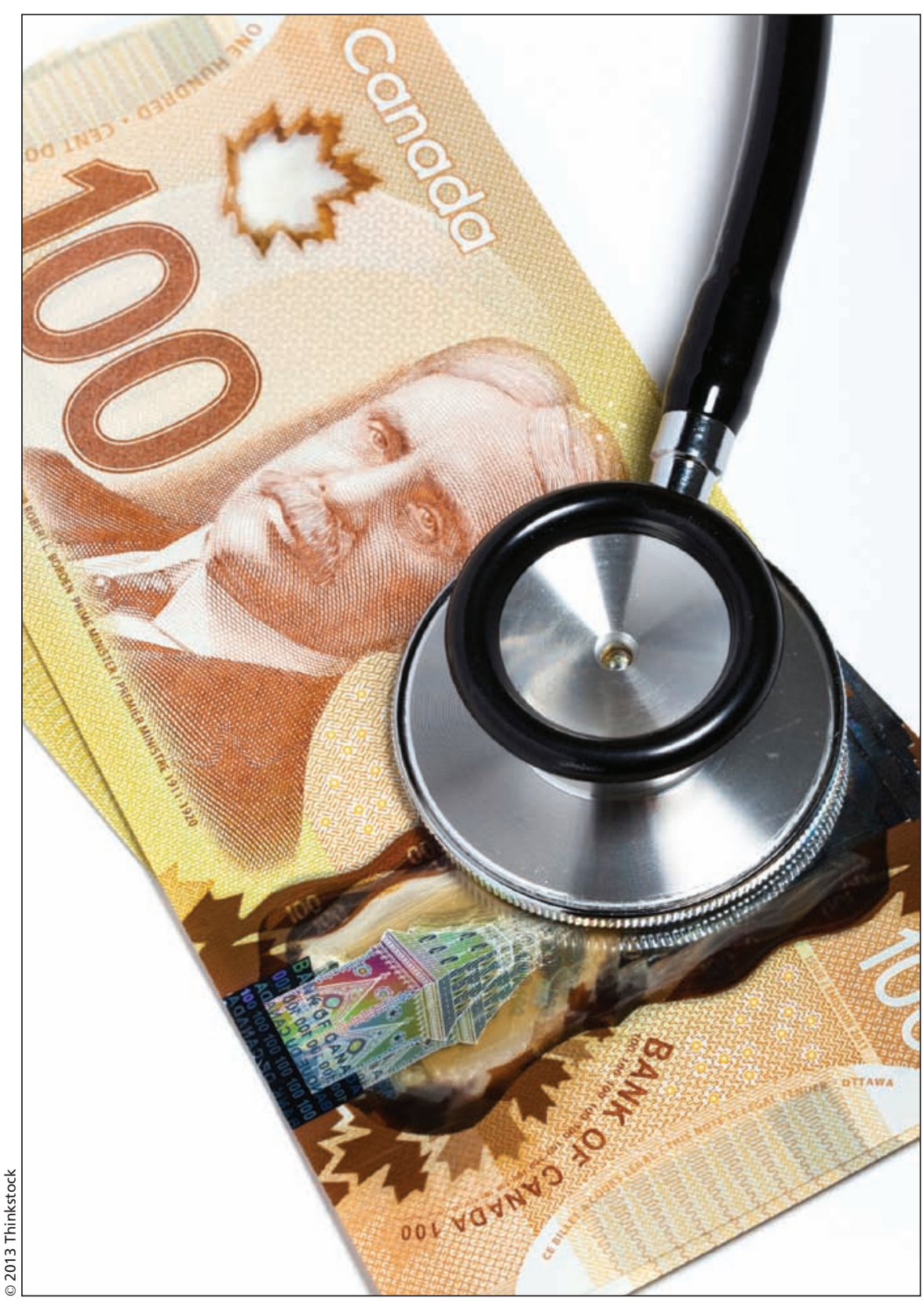

Using its new method of calculating physician earnings, the Canadian Institute of Health Information indicates that doctors grossed an average of \$307 482 in 2010-2011.

was occupied by Quebec (\$226 718). Other provinces that moved spots under the new metric include New Brunswick (dropping from third position to sixth) and Ontario (rising from fourth position to second).

Alternative clinical payments (salary, sessional, capitation, etc.) account for
$27.4 \%$ of all compensation, according to the report. In 1999-2000, by comparison, that figure was only $10.6 \%$. The proportion of total clinical payments that aren't of the fee-for-service variety also varies widely between provinces. In Nova Scotia, for example, $46.6 \%$ of payments were alternative, 
but in Alberta, only $14.8 \%$ came from outside the fee-for-service system.

Alternative forms of clinical payment may be on the rise as provinces attempt to revise the incentive structure for physicians, says Ballinger. "One of the limitations of fee-for-service is that it's very volume-driven. Doctors provide more services to increase their incomes. Many provinces have brought in alternative forms of payment with the intention that doctors wouldn't be so volume-driven."

Though it provides a more comprehensive picture of average physician compensation, incorporating alternative payments into its compensation calculations has a substantial limitation, according to Ballinger. The level of detail about alternative payments is far inferior to that about pay-for-service payments. For example, CIHI doesn't have enough data to report average gross clinical payment according to medical specialty.

"Many provinces do have that data and are currently sharing it with us, but we don't have it across the country," says Ballinger. (The provinces that have provided the specialist information are Newfoundland and Labrador, Nova Scotia, PEI, New Brunswick and British Columbia.)

The average gross fee-for-service income for specialists who received at least $\$ 60000$ in payments is listed by province. In Ontario, for example, internal medicine topped the list of medical specialities (\$409 994) and ophthalmology ranked highest for surgical specialities (\$702 023). In Newfoundland and Labrador, the lowest-paid medical specialty was neurology (\$226 918) and the lowest-paid surgical speciality was general surgery (\$319 967).

Overall, payments to Canadian physicians reached $\$ 20.2$ billion in 2010-2011, up 6\% from the previous year. This increase was smaller than the one seen in 2009-2010 (7.9\%) and 2008-2009 (9.7\%). Ontario doctors received the most money ( $\$ 8.3$ billion), more than double than that received by second-place Quebec. PEI physicians received the lowest amount for providing clinical services (\$75.7 million).

Other findings from National Physician Database 2010-2011 include:
- Canada has 65704 physicians. Ontario has the most (24 554). PEI has the least (321)

- Percentage of physicians paid mainly through alternative modes: $18.7 \%$

- Total number of medical services paid for by fee-for-service billings: 245.3 million

- Number of services provided by family physicians: 144.5 million

- Number of services provided by specialists: 100.8 million

- Average cost per medical service: $\$ 53.95$

- Average cost per service provided by a family physician: $\$ 39.85$

- Average cost per service provided by a specialist: $\$ 74.17$.

All physician payments are reported on the basis of gross, rather than net, income, the report states. "Because overhead expenses vary across jurisdictions and specialties and are not clearly reported, CIHI does not adjust payment figures to account for them." - Roger Collier, CMAJ

CMAJ 2013. DOI:10.1503/cmaj.109-4402 